\title{
Defective cholesterol clearance limits remyelination in the aged central nervous system
}

\author{
Ludovico Cantuti-Castelvetri, ${ }^{1,2,3,4 *}$ Dirk Fitzner, ${ }^{1,5 *}$ Mar Bosch-Queralt,, ${ }^{1,2,3,4}$ Marie-Theres Weil, ${ }^{1,6}$ Minhui \\ Su, ${ }^{1,2,3,4}$ Paromita Sen, ${ }^{1}$ Torben Ruhwedel, ${ }^{7}$ Miso Mitkovski, ${ }^{8}$ George Trendelenburg, ${ }^{7}$ Dieter Lütjohann, ${ }^{9}$ Wiebke \\ Möbius, ${ }^{6,7}$ Mikael Simons ${ }^{1,2,3,4, \uparrow}$ \\ ${ }^{1}$ Max Planck Institute of Experimental Medicine, 37075 Göttingen, Germany. ${ }^{2}$ Munich Cluster for Systems Neurology (SyNergy), 81377 Munich, Germany. ${ }^{3}$ Institute of \\ Neuronal Cell Biology, Technical University Munich, 80805 Munich, Germany. ${ }^{4}$ German Center for Neurodegenerative Disease (DZNE), 81377 Munich, Germany. \\ ${ }^{5}$ Department of Neurology, University of Göttingen Medical Center, 37075 Göttingen, Germany. ${ }^{6}$ Center Nanoscale Microscopy and Molecular Physiology of the Brain \\ (CNMPB), 37075 Göttingen, Germany. ${ }^{7}$ Department of Neurogenetics, Max Planck Institute of Experimental Medicine, 37075 Göttingen, Germany. ${ }^{8}$ Light Microscopy

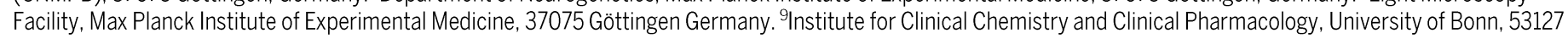 \\ Bonn, Germany. \\ *These authors contributed equally to this work. \\ †Corresponding author. Email: msimons@gwdg.de
}

Age-associated decline in regeneration capacity limits the restoration of nervous system functionality after injury. In a model for demyelination, we found that old mice fail to resolve the inflammatory response initiated after myelin damage. Aged phagocytes accumulated excessive amounts of myelin debris, which triggered cholesterol crystal formation, phagolysosomal membrane rupture, and stimulated inflammasomes. Myelin debris clearance required cholesterol transporters including apolipoprotein E. Remarkably, stimulation of reverse cholesterol transport was sufficient to restore the capacity of old mice to remyelinate lesioned tissue. Thus, cholesterol-rich myelin debris can overwhelm the efflux capacity of phagocytes, resulting in a phase transition of cholesterol into crystals thereby inducing a maladaptive immune response that impedes tissue regeneration.

Remyelination restores rapid transmission of nerve impulses and axonal function in the CNS of patients with demyelinating diseases such as multiple sclerosis (MS). Although remyelination can occur in MS, age-associated decline in myelin repair contributes to chronic progressive disease and disability (1). Thus, understanding the cause of and preventing this decline is a key goal in regenerative medicine (2-4). So far, epigenetic changes within aging oligodendrocyte progenitor cells and declines in phagocytic capacity of aged blood-derived monocytes have been identified as possible mechanisms $(5,6)$. We implemented a toxin-induced model, in which a single injection of lysolecithin (lysophosphatidylcholine) induces a focal demyelinating lesion in the white matter of the brain or spinal cord of mice. In lesioned animals, demyelination is complete within 4 days, followed by a repair process that is maximal between 14 to 21 days post injection (dpi) and requires rapid clearance of damaged myelin for regeneration to occur (7). We induced focal demyelinating lesions in the corpus callosum of young ( 3 months) and old (12 months) mice by lysolecithin injections. Lesions were of similar size at $4 \mathrm{dpi}$, but not at $14 \mathrm{dpi}$ confirming the poor regenerative capacity of old mice (Fig. 1, A to C, and fig. S1, A to E). Sustained immune infiltration, as determined by IBA1positive and MAC2-positive cells, was detected in old mice at

First release: 4 January 2018 14dpi (Fig. 1, A and E, and fig. S1G). Myelin debris accumulation within lysosomes of phagocytes (Fig. 1, D and F) and numerous foam cells harboring lipid droplets and needleshaped cholesterol crystals - a typical hallmark of cholesterol overloading - were found in old mice (Fig. 1, G and H, and fig. $\mathrm{S} 2 \mathrm{G})$. Moreover, by a combination of laser reflection and fluorescence confocal microscopy (reflection microscopy) we confirmed the increase of crystal deposition in spinal cord lesions of old mice (Fig. 1, I and J). Crystals were similarly observed in two other models of myelin injury (fig. S2).

Toxic overload of cholesterol drives the formation of foamy macrophages and maladaptive immune responses in atherosclerosis. We hypothesized that the accumulation of cholesterol, the major component of myelin, may overwhelm the cholesterol transport capacity of phagocytes, thereby forming a bottleneck for successful repair in the aged CNS. Because cholesterol cannot be broken down it needs to be transferred from the phagocytes back to the extracellular space using the transporters ATP-Binding Cassette A1 and G1 (ABCA1 and ABCG1) in the plasma membrane where it binds high-density lipoprotein particles (e.g., APOE) (8). Real-time quantitative reverse transcription PCR revealed that the expression of $A p o E, A b c a 1$ and $A b c g 1$, was reduced in 4 dpi lesions of old compared to young mice (Fig. 1, K to M, and fig. S3). Oxysterols (hydroxylated cholesterol metabolites) such 
as 24S- and 27-hydroxycholesterol are endogenous ligands for liver X receptor (LXR), thereby controlling the expression of genes involved in cholesterol efflux in cholesterol-loaded cells (9). Relative amounts of 24S-hydroxycholesterol did not differ in lesions of young and old animals, but 27-hydroxycholesterol levels were reduced in lesions of old mice (fig. S3). One possible explanation for lesion restitution failure in old mice is the inability to clear excessive myelin-derived cholesterol from phagocytes. Thus, we examined whether the LXR agonist, GW3965 (10) improve lesion recovery in old mice by inducing the expression of genes involved in lipid efflux, such as Abca1, Abcg1 and ApoE (fig. S3). GW3965 led to markedly improved lesion regeneration in old mice with a reduction in the number of IBA1-positive and MAC2-positive phagocytes (Fig. 1, A to C). In addition, the number of phagocytes containing myelin debris, the number of foam cells and the amount of cholesterol crystals was reduced by treatment with GW3965 (Fig. 1, A to J).

Because accumulation of cholesterol in phagocytes may pose a barrier for successful tissue regeneration, we analyzed the regenerative capacity of mouse mutants lacking central factors of the reverse cholesterol transport pathway. We induced demyelinating lesions in 3 month old NR1H3 (or $\mathrm{LXR} \alpha)$ knockout mice and observed, as in aged wild-type mice, impaired lesion restitution and sustained phagocyte infiltration at $21 \mathrm{dpi}$ (fig. S4, A to C). In addition, we detected accumulation of myelin debris in lysosomes of phagocytes and crystal deposition in lesions of LXR $\alpha$ KO mice (fig. S4, D to $G$ ).

Next, we analyzed the role of apolipoprotein E (APOE), the major CNS cholesterol carrier that supports lipid efflux from cells (11). We induced focal demyelination in the corpus callosum of 12-week old APOE knockout (APOE KO) and wild-type control mice and quantified lesion size and recovery. Lesion size did not differ initially, at 4 dpi (fig. S4, H to J). However, when lesions were analyzed at $21 \mathrm{dpi}$, we observed impaired lesion restitution. We detected an increased number of IBA1-positive, MAC2-positive and MHCII-positive phagocytes, crystal deposition and myelin debris accumulation within lysosomes of phagocytes in spinal cord and corpus callosum lesions of APOE KO animals as compared to control mice (Fig. 2 and fig. S5). Because APOE has functions beyond cholesterol transport (11), we tested the efficacy of cyclic oligosaccharide 2-hydroxypropyl- $\beta$-cyclodextrin $(\mathrm{H} \beta \mathrm{CD})$, a compound that increases cholesterol efflux and solubility (12); and found that $\mathrm{H} \beta \mathrm{CD}$ treatment attenuated the phenotype of APOE KO animals (Fig. 3 and fig. S6).

$A p o E$ represents together with $A b c a 1$ and $A b c g 1$ the major nuclear liver $\mathrm{X}$ receptor regulated genes that are involved in mediating cholesterol efflux from phagocytes. We thus crossbred CX3CR1CreER animals with Abca ${ }^{\mathrm{fl} / \mathrm{fl}}$ and Abcg $1^{\mathrm{t} / \mathrm{fl}}$ mice to obtain microglia/macrophage specific double knockout mice (ABCA1/G1 KO). We observed an increased number of IBA1-positive and MHCII-positive phagocytes, an increase in crystal deposition and fewer myelinated axons in 21 dpi lesions of $\mathrm{ABCA1} / \mathrm{G1} \mathrm{KO}$ animals as compared to control (fig. S7).

Because excessive cholesterol accumulation in phagocytes limits lesion recovery, we turned to cell culture experiments to determine the mechanisms involved. We prepared phagocytes (primary microglia or bone marrow-derived macrophages) from APOE KO and wild-type mice and examined the phagocytic uptake of myelin debris, which did not differ in cells prepared from wild-type or APOE KO mice (fig. S8, A and B). Because APOE is also produced by astrocytes, we incubated cells in the presence of serum-free conditioned media prepared from either wild-type or APOE KO astrocytes and observed the clearance of the internalized myelin particles from phagocytes. Myelin debris persisted within lysosomes of APOE KO cells that were incubated with conditioned media from APOE KO astrocytes. Clearance could be improved by an APOE-derived mimetic peptide, ATI5261 (13), which contains an amphipathic $\alpha$-helical motif responsible for lipid binding and cholesterol efflux (Fig. 3, E and F). Moreover, myelin debris treatment resulted in crystal formation, which was increased in APOE KO macrophages and reduced by GW3965 treatment (fig. S8, C to G).

In atherosclerosis, cholesterol crystals can induce inflammation by phagolysosomal membrane rupture and subsequent stimulation of the caspase-1-activating NLRP3 (NALP3 or cryopyrin) inflammasome and secretion of interleukin (IL)-1 cytokines $(14,15)$. Myelin debris treatment resulted in lysosomal permeabilization and caspase-1 cleavage in wildtype, but not in NLRP3-deficient macrophages (Fig. 4, A to H, and fig. S9, A and B). More pronounced caspase-1 activation was observed in APOE KO as compared to wild-type macrophages, which was confirmed in vivo in APOE KO mice after lysolecithin injection (Fig. 4E and fig. S9C). Myelin overloading induced cell death, which resulted in DNA fragmentation (detected by TUNEL assay), was cholesterol-dependent (fig. S9, D and E), and rescued by caspase-1 inhibitors pointing to an inflammasome-mediated pyroptotic cell death pathway (Fig. 4G and fig. S10). Thus, cholesterol derived from myelin debris can activate the NLRP3 inflammasome in macrophages when toxic levels build up intracellularly in the absence of sufficient lipoprotein carriers.

Because jamming the lysosomal system with myelin debris resulted in cholesterol crystallization and inflammasome activation, we asked whether this pathway was responsible for limiting regeneration in old mice. To examine whether increased inflammasome activation contributed to the poor recovery of old mice, we analyzed spinal cord lesions of aged wild-type and NLRP3-deficient mice. As in GW3965 treated old animals (Fig. 4, I and J), we found significantly improved 
remyelination in aged NLRP3-deficient mice as compared to aged wild-type mice at $21 \mathrm{dpi}$. Thus, inflammasome activation possibly downstream of cholesterol accumulation drives a maladaptive immune response impairing inflammation resolution and repair in aged mice.

Self-resolving inflammation is essential for a proper restorative process after tissue damage, while uncontrolled inflammation can leave lasting marks that permanently alter tissue homeostasis (16). Here, we made the surprising finding that the self-limiting inflammatory response, which is necessary to initiate a regenerative process, is maladaptive in the CNS of aged mice. It appears that the inability of aged phagocytes to clear the enormous amounts of cholesterol that are released from myelin after myelin breakdown in demyelinating diseases results in a phase transition of free cholesterol into crystals, inducing lysosomal rupture and inflammasome stimulation, which is consistent with the beneficial effects of nuclear receptor agonists in remyelination $(17,18)$. The unexpected link between lipid metabolisms and tissue regeneration provides opportunities for the development of regenerative medicines for remyelination and for improving functional recovery after CNS injury (19).

\section{REFERENCES AND NOTES}

1. P. Patrikios, C. Stadelmann, A. Kutzelnigg, H. Rauschka, M. Schmidbauer, H. Laursen, P. S. Sorensen, W. Brück, C. Lucchinetti, H. Lassmann, Remyelination is extensive in a subset of multiple sclerosis patients. Brain 129, 3165-3172 (2006). doi:10.1093/brain/awl217 Medline

2. F. J. Najm, M. Madhavan, A. Zaremba, E. Shick, R. T. Karl, D. C. Factor, T. E. Miller, Z. S. Nevin, C. Kantor, A. Sargent, K. L. Quick, D. M. Schlatzer, H. Tang, R. Papoian, K. R. Brimacombe, M. Shen, M. B. Boxer, A. Jadhav, A. P. Robinson, J. R. Podojil, S. D. Miller, R. H. Miller, P. J. Tesar, Drug-based modulation of endogenous stem cells promotes functional remyelination in vivo. Nature 522, 216-220 (2015). doi:10.1038/nature14335Medline

3. F. Mei, S. P. J. Fancy, Y.-A. A. Shen, J. Niu, C. Zhao, B. Presley, E. Miao, S. Lee, S. R. Mayoral, S. A. Redmond, A. Etxeberria, L. Xiao, R. J. M. Franklin, A. Green, S. L. Hauser, J. R. Chan, Micropillar arrays as a high-throughput screening platform for therapeutics in multiple sclerosis. Nat. Med. 20, 954-960 (2014). doi:10.1038/nm.3618 Medline

4. V. A. Deshmukh, V. Tardif, C. A. Lyssiotis, C. C. Green, B. Kerman, H. J. Kim, K. Padmanabhan, J. G. Swoboda, I. Ahmad, T. Kondo, F. H. Gage, A. N. Theofilopoulos, B. R. Lawson, P. G. Schultz, L. L. Lairson, A regenerative approach to the treatment of multiple sclerosis. Nature 502, 327-332 (2013). doi:10.1038/nature12647 Medline

5. J. M. Ruckh, J.-W. Zhao, J. L. Shadrach, P. van Wijngaarden, T. N. Rao, A. J. Wagers, R. J. M. Franklin, Rejuvenation of regeneration in the aging central nervous system. Cell Stem Cell 10, 96-103 (2012). doi:10.1016/j.stem.2011.11.019 Medline

6. S. Shen, J. Sandoval, V. A. Swiss, J. Li, J. Dupree, R. J. M. Franklin, P. CasacciaBonnefil, Age-dependent epigenetic control of differentiation inhibitors is critical for remyelination efficiency. Nat. Neurosci. 11, 1024-1034 (2008), doi:10.1038/nn.2172 Medline

7. V. E. Miron, A. Boyd, J.-W. Zhao, T. J. Yuen, J. M. Ruckh, J. L. Shadrach, P. van Wijngaarden, A. J. Wagers, A. Williams, R. J. M. Franklin, C. Ffrench-Constant, M2 microglia and macrophages drive oligodendrocyte differentiation during CNS remyelination. Nat. Neurosci. 16, 1211-1218 (2013). doi:10.1038/nn.3469 Medline

8. K. J. Moore, I. Tabas, Macrophages in the pathogenesis of atherosclerosis. Cell 145, 341-355 (2011). doi:10.1016/j.cell.2011.04.005 Medline

9. X. Fu, J. G. Menke, Y. Chen, G. Zhou, K. L. MacNaul, S. D. Wright, C. P. Sparrow, E. G. Lund, 27-hydroxycholesterol is an endogenous ligand for liver $X$ receptor in cholesterol-loaded cells. J. Biol. Chem. 276, 38378-38387 (2001).
doi:10.1074/ibc.M105805200 Medline

10. C. Hong, P. Tontonoz, Liver X receptors in lipid metabolism: Opportunities for drug discovery. Nat. Rev. Drug Discov. 13, 433-444 (2014). doi:10.1038/nrd4280 Medline

11. R. W. Mahley, Apolipoprotein E: Cholesterol transport protein with expanding role in cell biology. Science 240, 622-630 (1988). doi:10.1126/science.3283935 Medline

12. S. Zimmer, A. Grebe, S. S. Bakke, N. Bode, B. Halvorsen, T. Ulas, M. Skjelland, D. De Nardo, L. I. Labzin, A. Kerksiek, C. Hempel, M. T. Heneka, V. Hawxhurst, M. L. Fitzgerald, J. Trebicka, I. Björkhem, J.-A. Gustafsson, M. Westerterp, A. R. Tall, S. D. Wright, T. Espevik, J. L. Schultze, G. Nickenig, D. Lütjohann, E. Latz, Cyclodextrin promotes atherosclerosis regression via macrophage reprogramming. Sci. Transl. Med. 8, 333 ra50 (2016). doi:10.1126/scitranslmed.aad6100 Medline

13. A. Hafiane, J. K. Bielicki, J. O. Johansson, J. Genest, Apolipoprotein E derived HDL mimetic peptide ATI-5261 promotes nascent HDL formation and reverse cholesterol transport in vitro. Biochim. Biophys. Acta $1841 \quad$, 1498-1512 (2014). doi:10.1016/j.bbalip.2014.07.018 Medline

14. P. Duewell, H. Kono, K. J. Rayner, C. M. Sirois, G. Vladimer, F. G. Bauernfeind, G. S. Abela, L. Franchi, G. Nuñez, M. Schnurr, T. Espevik, E. Lien, K. A. Fitzgerald, K. L. Rock, K. J. Moore, S. D. Wright, V. Hornung, E. Latz, NLRP3 inflammasomes are required for atherogenesis and activated by cholesterol crystals. Nature 464, 1357-1361 (2010). doi:10.1038/nature08938 Medline

15. K. Rajamäki, J. Lappalainen, K. Oörni, E. Välimäki, S. Matikainen, P. T. Kovanen, K. K. Eklund, Cholesterol crystals activate the NLRP3 inflammasome in human macrophages: A novel link between cholesterol metabolism and inflammation. PLOS ONE 5, e11765 (2010). doi:10.1371/journal.pone.0011765 Medline

16. A. Aguzzi, B. A. Barres, M. L. Bennett, Microglia: Scapegoat, saboteur, or something else? Science 339, 156-161 (2013). doi:10.1126/science.1227901 Medline

17. J. K. Huang, A. A. Jarjour, B. N. Oumesmar, C. Kerninon, A. Williams, W. Krezel, H. Kagechika, J. Bauer, C. Zhao, A. Baron-Van Evercooren, P. Chambon, C. FfrenchConstant, R. J. M. Franklin, Retinoid X receptor gamma signaling accelerates CNS remyelination. Nat. Neurosci. 14, 45-53 (2011). doi:10.1038/nn.2702 Medline

18. D. Meffre, G. Shackleford, M. Hichor, V. Gorgievski, E. T. Tzavara, A. Trousson, A. M. Ghoumari, C. Deboux, B. Nait Oumesmar, P. Liere, M. Schumacher, E.-E. Baulieu, F. Charbonnier, J. Grenier, C. Massaad, Liver X receptors alpha and beta promote myelination and remyelination in the cerebellum. Proc. Natl. Acad. Sci. U.S.A. 112, 7587-7592 (2015). doi:10.1073/pnas.1424951112 Medline

19. F. Bei, H. H. C. Lee, X. Liu, G. Gunner, H. Jin, L. Ma, C. Wang, L. Hou, T. K. Hensch, E. Frank, J. R. Sanes, C. Chen, M. Fagiolini, Z. He, Restoration of visual function by enhancing conduction in regenerated axons. Cell 164, 219-232 (2016). doi:10.1016/j.cell.2015.11.036 Medline

20. J. A. Piedrahita, S. H. Zhang, J. R. Hagaman, P. M. Oliver, N. Maeda, Generation of mice carrying a mutant apolipoprotein $\mathrm{E}$ gene inactivated by gene targeting in embryonic stem cells. Proc. Natl. Acad. Sci. U.S.A. 89, 4471-4475 (1992). doi:10.1073/pnas.89.10.4471 Medline

21. G. Liang, J. Yang, J. D. Horton, R. E. Hammer, J. L. Goldstein, M. S. Brown, Diminished hepatic response to fasting/refeeding and liver $X$ receptor agonists in mice with selective deficiency of sterol regulatory element-binding protein-1c. J. Biol. Chem. 277, 9520-9528 (2002). doi:10.1074/jbc.M111421200 Medline

22. M. Westerterp, S. Gourion-Arsiquaud, A. J. Murphy, A. Shih, S. Cremers, R. L. Levine, A. R. Tall, L. Yvan-Charvet, Regulation of hematopoietic stem and progenitor cell mobilization by cholesterol efflux pathways. Cell Stem Cell 11, 195206 (2012). doi:10.1016/i.stem.2012.04.024 Medline

23. S. Yona, K.-W. Kim, Y. Wolf, A. Mildner, D. Varol, M. Breker, D. Strauss-Ayali, S. Viukov, M. Guilliams, A. Misharin, D. A. Hume, H. Perlman, B. Malissen, E. Zelzer, $\mathrm{S}$. Jung, Fate mapping reveals origins and dynamics of monocytes and tissue macrophages under homeostasis. Immunity 38, 79-91 (2013). doi:10.1016/j.immuni.2012.12.001 Medline

24. S. Safaiyan, N. Kannaiyan, N. Snaidero, S. Brioschi, K. Biber, S. Yona, A. L. Edinger, S. Jung, M. J. Rossner, M. Simons, Age-related myelin degradation burdens the clearance function of microglia during aging. Nat. Neurosci. 19, 995-998 (2016). doi:10.1038/nn.4325 Medline

25. E. O. Samstad, N. Niyonzima, S. Nymo, M. H. Aune, L. Ryan, S. S. Bakke, K. T. 
Lappegård, O.-L. Brekke, J. D. Lambris, J. K. Damås, E. Latz, T. E. Mollnes, T. Espevik, Cholesterol crystals induce complement-dependent inflammasome activation and cytokine release. J. Immunol. 192, 2837-2845 (2014). doi:10.4049/jimmunol.1302484 Medline

26. C. Oberle, J. Huai, T. Reinheckel, M. Tacke, M. Rassner, P. G. Ekert, J. Buellesbach, C. Borner, Lysosomal membrane permeabilization and cathepsin release is a Bax/Bak-dependent, amplifying event of apoptosis in fibroblasts and monocytes. Cell Death Differ. 17, 1167-1178 (2010). doi:10.1038/cdd.2009.214 Medline

27. N. Snaidero, W. Möbius, T. Czopka, L. H. P. Hekking, C. Mathisen, D. Verkleij, S. Goebbels, J. Edgar, D. Merkler, D. A. Lyons, K.-A. Nave, M. Simons, Myelin membrane wrapping of CNS axons by PI $(3,4,5) \mathrm{P} 3$-dependent polarized growth at the inner tongue. Cell 156, 277-290 (2014). doi:10.1016/j.cell.2013.11.044 Medline

28. D. Lütjohann, C. Hahn, W. Prange, T. Sudhop, M. Axelson, T. Sauerbruch, K. von Bergmann, C. Reichel, Influence of rifampin on serum markers of cholesterol and bile acid synthesis in men. Int. J. Clin. Pharmacol. Ther. 42, 307-313 (2004). doi:10.5414/CPP42307 Medline

29. K. M. Thelen, K. M. Rentsch, U. Gutteck, M. Heverin, M. Olin, U. Andersson, A. von Eckardstein, I. Björkhem, D. Lütjohann, Brain cholesterol synthesis in mice is affected by high dose of simvastatin but not of pravastatin. J. Pharmacol. Exp. Ther. 316, 1146-1152 (2006). doi:10.1124/jpet.105.094136 Medline

\section{ACKNOWLEDGMENTS}

We thank L. Vaculčiaková for help with the calculations of 3D reconstructions. The technical assistance of A. Kerksiek is gratefully acknowledged. The work was supported by an ERC CoG Grant (M.S.) and grants from the German Research Foundation (SI 746/9-1,10-1, SPP1757, TRR128, TRR43), the Tschira-Stiftung, the Adelson Foundation, the Cluster of Excellence and DFG Research Center CNMBP (W.M.) and SyNergy (M.S.). W.M. is supported by an ERC Grant to K.-A. Nave. M.B.Q. is supported by a Boehringer Ingelheim stipend. All data are presented in the main text and supplementary materials.

\section{SUPPLEMENTARY MATERIALS}

www.sciencemag.org/cgi/content/full/science.aan4183/DC1

Materials and Methods

Figs. S1 to S10

References (20-29)

10 April 2017; resubmitted 5 November 2017

Accepted 11 December 2017

Published online 4 January 2018

10.1126/science.aan4183 
A
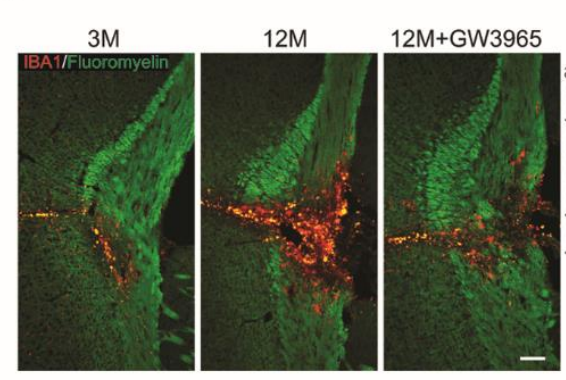

D

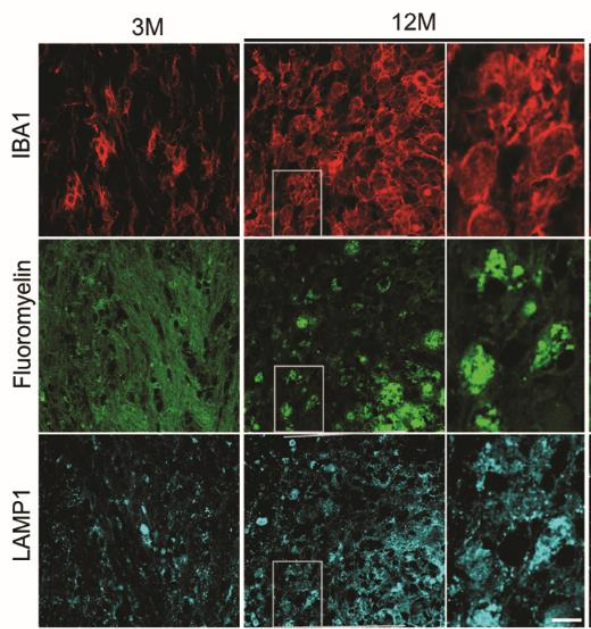

G

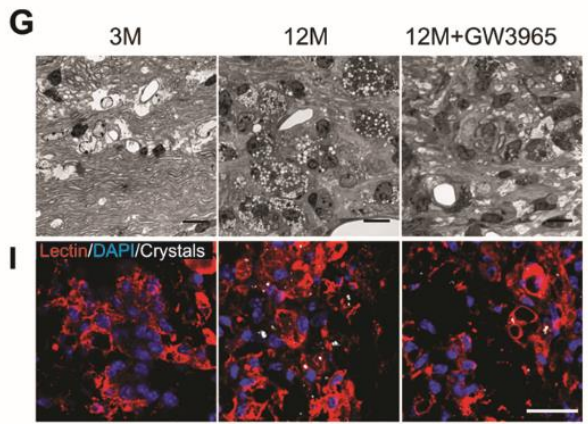

K

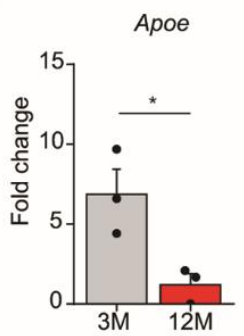

L

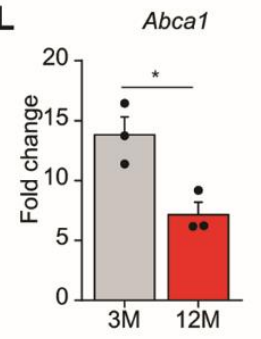

B

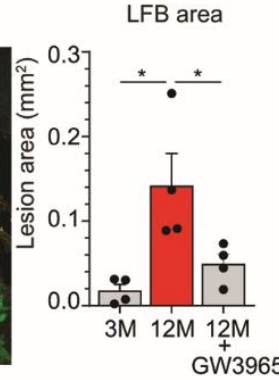

C

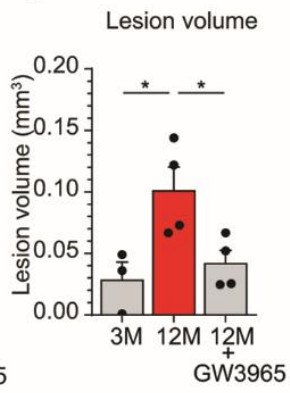

E

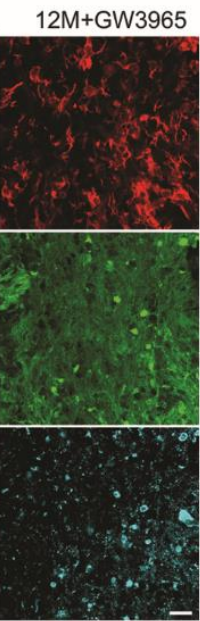

H
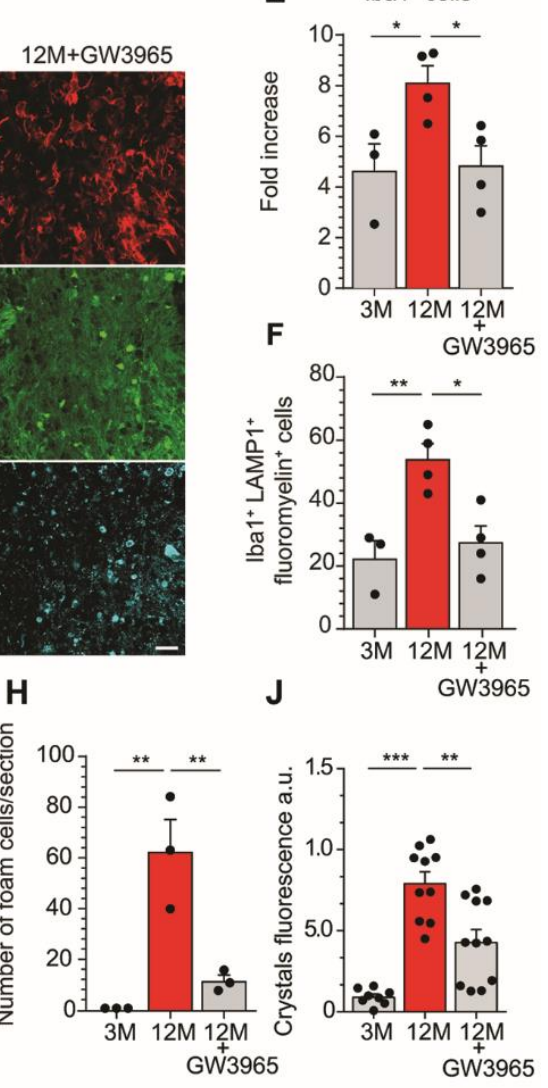

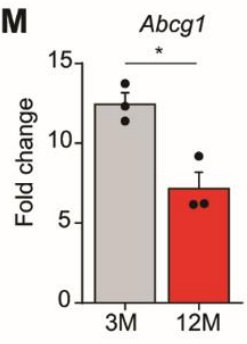

Fig. 1. Defective cholesterol clearance limits lesion regeneration in aged mice. (A) Images of corpus callosum lesions stained with fluoromyelin (green) and IBA1 (red) in 3 month old (3M), 12 month old (12M) and 12 month old mice treated with GW3965 (12M+GW3965) at 14 dpi. Scale bar, $100 \mu \mathrm{m}$. (B and C) Quantification of lesion area in $\mathrm{mm}^{2}$ determined by luxol fast blue (LFB) and in $\mathrm{mm}^{3}$ by fluoromyelin staining at $14 \mathrm{dpi}$. (D) Confocal images of $3 \mathrm{M}, 12 \mathrm{M}$ and 12M+GW3965 corpus callosum lesions showing IBA1 (red), fluoromyelin (green)

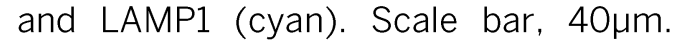
Magnified images of the boxed areas are show next to the images. (E) Change in number of IBA1 ${ }^{+}$cells in corpus callosum lesions compared to contralateral unlesioned side. (F) Number of IBA $1^{+} /$fluoromyelin ${ }^{+} / \mathrm{LAMP}^{+}$cells in lesioned corpus callosum at 14 dpi. (G) Semithin section and $(H)$ quantification of foam cells of $3 \mathrm{M}, 12 \mathrm{M}$ and $12 \mathrm{M}+\mathrm{GW} 3965$ corpus callosum lesions. Scale bar, 10 $\mu \mathrm{m}$. (I) Reflection microscopy images of spinal cord lesions, showing crystals (white) in lectin ${ }^{+}$phagocytes (red), and $(\mathrm{J})$ relative quantification of the fluorescence intensity of the reflected light. Scale bar, $25 \mu \mathrm{m}$. ( $\mathrm{K}$ to $\mathrm{M}$ ) Quantitative PCR analysis of Apoe, Abcal and Abcg1 in $4 \mathrm{dpi}$ lesions of $3 \mathrm{M}$ and $12 \mathrm{M}$ mice. All data are mean \pm SEM; ${ }^{*} P<0.05$, ${ }^{*} \mathrm{P}<0.01$, ${ }^{* *} \mathrm{P}<0.001$ by one way ANOVA test, with Tukey's multiple comparison test. 

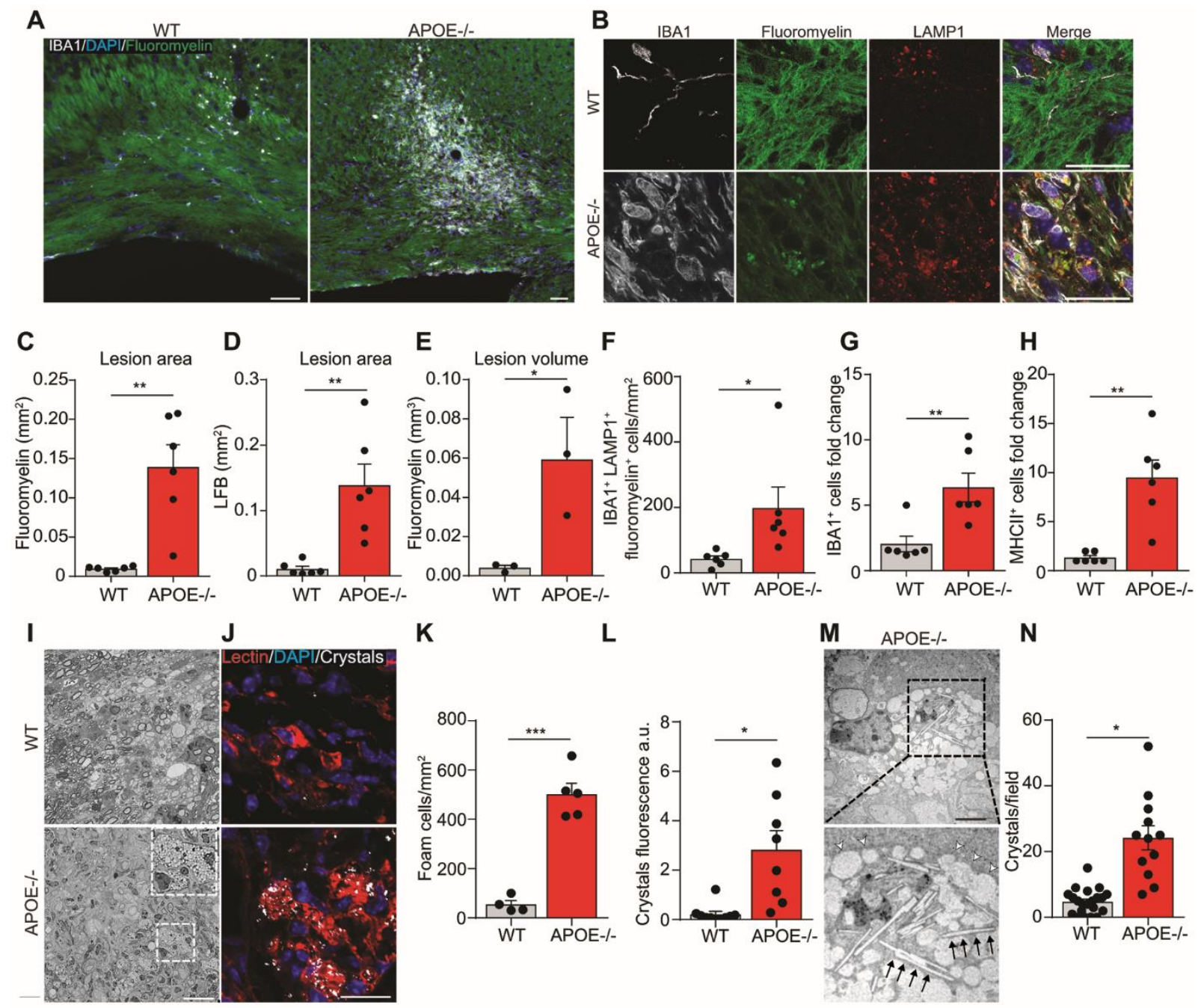

Fig. 2. APOE is required for cholesterol clearance in demyelinating lesions. (A and B) Images of corpus callosum lesions in WT and APOE-/- mice at 21 dpi showing fluoromyelin staining (green), IBA1 (white), DAPI (blue) and LAMP1 (red). (C and D) Quantification of lesion area in $\mathrm{mm}^{2}$ at $21 \mathrm{dpi}$ as determined by fluoromyelin and luxol fast blue (LFB) staining. (E) Lesion volume in $\mathrm{mm}^{3}$ measured by fluoromyelin staining in consecutive sections. (F) Number of $\mid \mathrm{BA}^{+} /$ fluoromyelin ${ }^{+} / \mathrm{LAMP1}^{+}$cells per $\mathrm{mm}^{2}$ in lesions at $21 \mathrm{dpi}$. ( $\mathrm{G}$ and $\mathrm{H}$ ) Change in the number of IBA ${ }^{+}$ and $\mathrm{MHC} \mathrm{II}$ cells in the lesioned corpus callosum as compared to the contralateral unlesioned side. (I) Representative images (boxed area shown at larger magnification in right corner) and (K) quantification of foam cells in spinal cord lesions in WT and APOE-/- mice at $21 \mathrm{dpi}$. (J) Reflection microscopy images of 21 dpi lysolecithin lesions, showing crystals (white) in lectin ${ }^{+}$phagocytes (red), and (L) relative quantification of the fluorescence intensity of the reflected light. (M) Transmission electron microscopy images of foam cells in 21 dpi lesions of APOE-/- mice (boxed area shown below at higher magnification), showing needle-like cholesterol crystals (black arrows) and lipid droplets (white arrowheads), and ( $\mathrm{N}$ ) relative quantification of crystals. All data are mean $\pm \mathrm{SEM}$; ${ }^{*} \mathrm{P}<0.05$, ${ }^{*} \mathrm{P}<0.01$, ${ }^{* *} \mathrm{P}<0.001$, two-tailed Student's $t$-test. Scale bars in $(A$, $\mathrm{B}, \mathrm{I}$, and $\mathrm{J}$ ) are $25 \mu \mathrm{m}$; scale bar in (K) is $2.5 \mu \mathrm{m}$. 
A
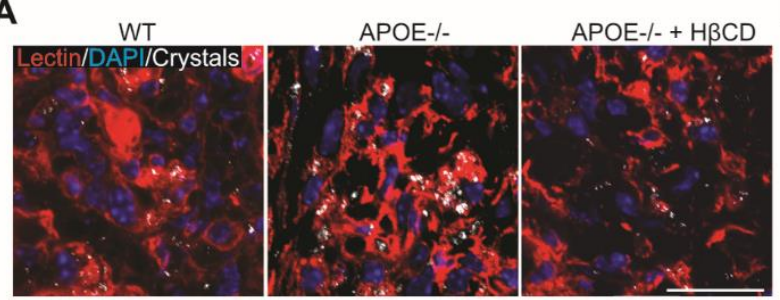

C

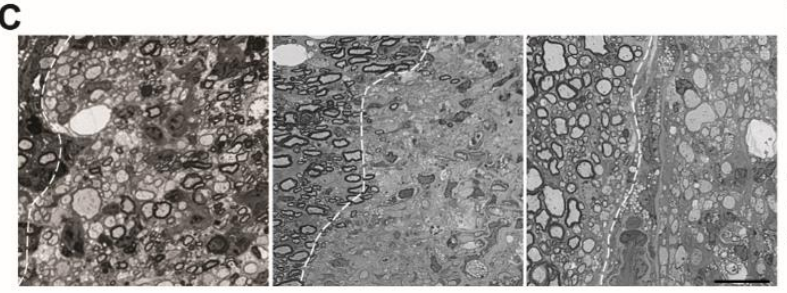

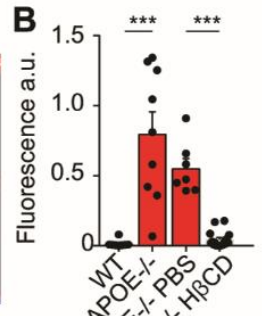

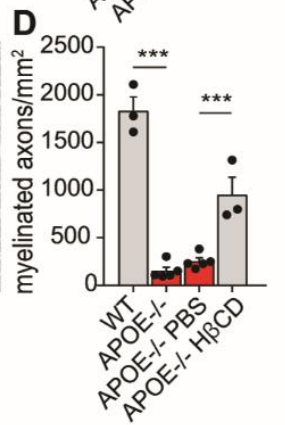

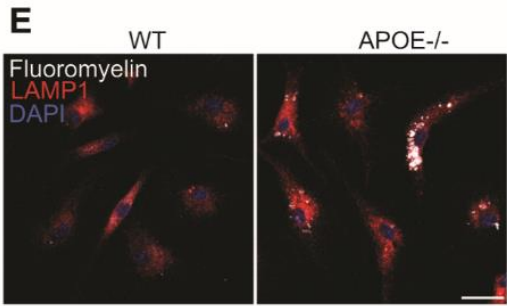

$\mathbf{F}$

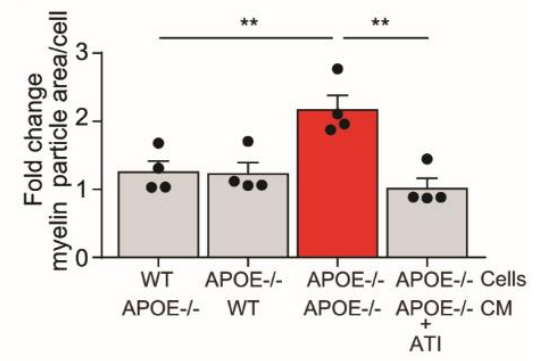

Fig. 3. Enhancing cholesterol clearance prevents lysosomal storage of myelin debris and crystal formation. (A) Representative images with crystals (white) and lectin ${ }^{+}$phagocytes (red); and (B) quantification of cholesterol crystals in lysolecithin lesions of WT, APOE-/- and APOE-/- mice treated with HBCD or PBS. (C) Representative images of Methylenblue-Azur II staining and (D) quantification of remyelination in lysolecithin lesions at $21 \mathrm{dpi}$. The edges of the lesions are identified by a dashed line. (E) Confocal images of primary microglial cell cultures prepared from WT or APOE-/- mice, treated with myelin debris and stained for LAMP1 (red), fluoromyelin (white) and DAPI (dark blue) at 24 hours post-treatment. Microglia from WT or APOE-/- mice were treated with myelin debris and subsequently transferred in media conditioned (CM) either by WT or APOE-/astrocytes. APOE-/- microglia cells in APOE-/- conditioned media were additionally treated with APOE mimetic peptide (ATI). (F) Change in the area of myelin particles per cell as compared to WT cells in WT conditioned media. All data are mean $\pm \mathrm{SEM}$; ${ }^{*} \mathrm{P}<0.05$, ${ }^{*} \mathrm{P}<0.01$, ${ }^{*}{ }^{*} \mathrm{P}<0.001$, by two way ANOVA, with Tukey's multiple comparison test. Scale bar is $25 \mu \mathrm{m}$ in (A); scale bar is $100 \mu \mathrm{m}$ in (B). 
A

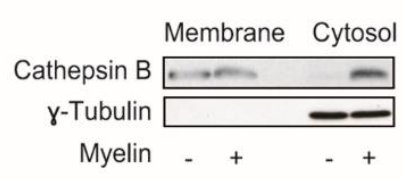

E

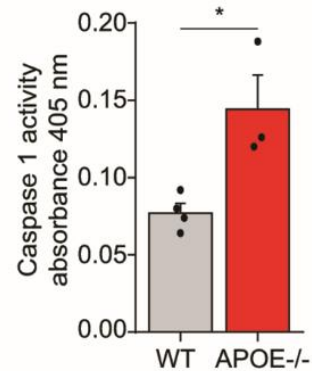

B

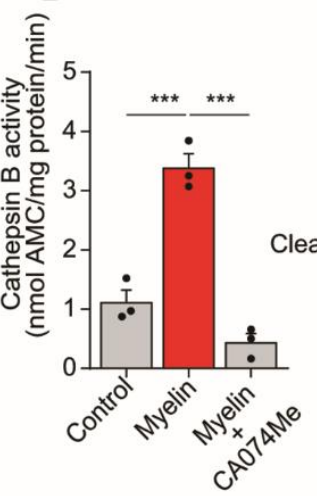

$\mathbf{F}$

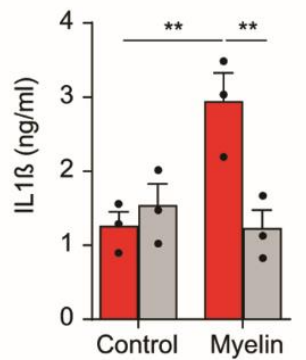

C

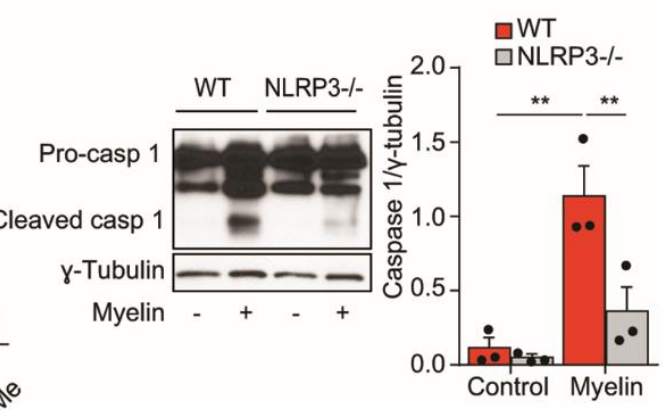

G

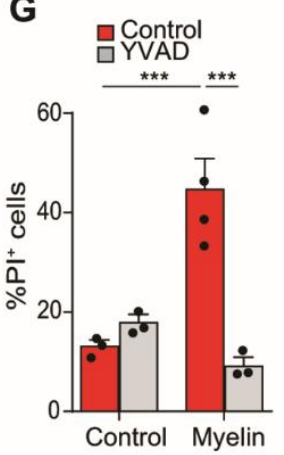

H

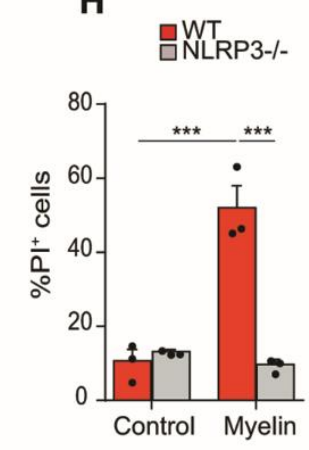

$\mathbf{J}$

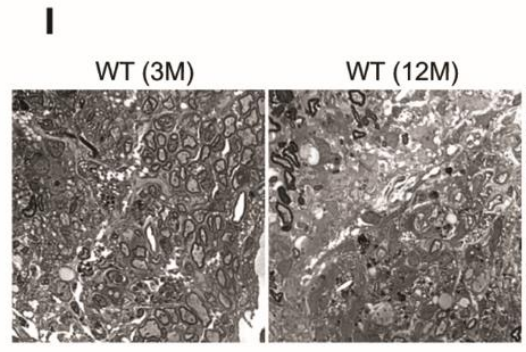

WT $(12 M)+$ GW3965
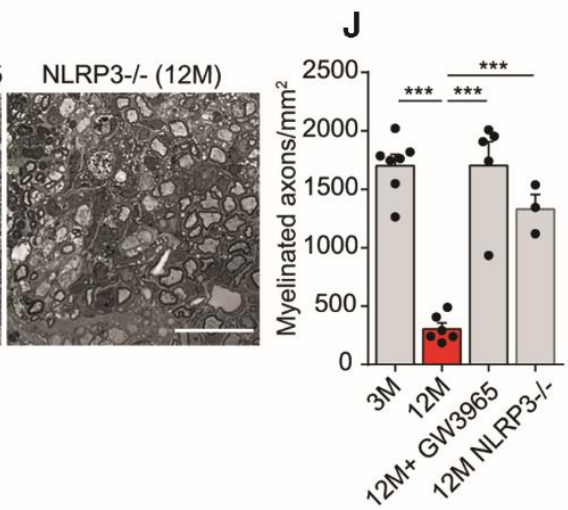

Fig. 4. Defective myelin debris clearance activates the NLRP3 inflammasome. (A) Immunoblot of cytosol and membrane fractions of primary bone marrow-derived macrophages (BMDM) 12 hours after treatment with myelin debris for cathepsin B and $\gamma$-tubulin. (B) Cathepsin B activity assay of the cytosolic fraction of control macrophages 12 hours after treatment with myelin debris in the presence or absence

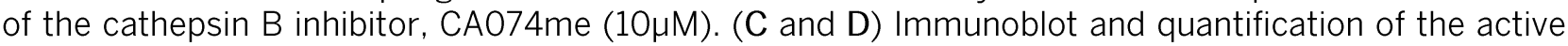
subunit of caspase 1 (p20) after myelin debris treatment of WT or NLRP3-/- BMDM. The intensity of the p20 band was normalized to $\gamma$-tubulin. (E) Caspase 1 activity in lysates from lysolecithin lesions of WT and APOE-/- mice at 21 dpi. (F) ELISA for IL1 $\beta$ release in WT BMDM, after treatment with myelin debris with or without YVAD. (G) Quantification of the percentage of dead cells (propidium iodide positive, $\mathrm{Pl}^{+}$) after myelin debris treatment (12 hours) in the presence or absence of caspase 1 inhibitor (YVAD). (H) Quantification of $\mathrm{Pl}^{+}$cells after treatment of WT and NLRP3-/- BMDM with myelin debris for $12 \mathrm{~h}$. (I) Methylenblue-Azur II staining of remyelinating lesions in the spinal cord of 3M, 12M, GW3965 treated 12 $\mathrm{M}$, and $12 \mathrm{M}$ old NLRP3 $-/-$ mice and $(\mathrm{J})$ relative quantification of myelinated fibers. All data are mean \pm SEM; ${ }^{*} \mathrm{P}<0.05$, ${ }^{* *} \mathrm{P}<0.01$, ${ }^{* *} \mathrm{P}<0.001$ by one way ANOVA test, with Tukey's multiple comparison test and two-tailed Student's t-test (E). Scale bar, $25 \mu \mathrm{m}$. 


\section{Science}

\section{Defective cholesterol clearance limits remyelination in the aged central nervous system}

Ludovico Cantuti-Castelvetri, Dirk Fitzner, Mar Bosch-Queralt, Marie-Theres Weil, Minhui Su, Paromita Sen, Torben Ruhwedel, Miso Mitkovski, George Trendelenburg, Dieter Lütjohann, Wiebke Möbius and Mikael Simons

published online January 4, 2018

ARTICLE TOOLS

SUPPLEMENTARY

MATERIALS

REFERENCES

PERMISSIONS http://science.sciencemag.org/content/early/2018/01/03/science.aan4183

http://science.sciencemag.org/content/suppl/2018/01/03/science.aan4183.DC1

This article cites 29 articles, 9 of which you can access for free http://science.sciencemag.org/content/early/2018/01/03/science.aan4183\#BIBL

http://www.sciencemag.org/help/reprints-and-permissions

Use of this article is subject to the Terms of Service

Science (print ISSN 0036-8075; online ISSN 1095-9203) is published by the American Association for the Advancement of Science, 1200 New York Avenue NW, Washington, DC 20005. 2017 (C) The Authors, some rights reserved; exclusive licensee American Association for the Advancement of Science. No claim to original U.S. Government Works. The title Science is a registered trademark of AAAS. 